\title{
Defect Investigation of Some Commercial Aluminum Alloys by Doppler Broadening Technique
}

\author{
E. A. Badawi*, M. Abdel-Rahman ${ }^{* *}$, A. G. Attallah and M. Abdel-Nasser \\ Physics Department, Faculty of Science, Minia University, P.O. 61519, Egypt
}

\begin{abstract}
OPPLER broadening is a sensitive non-destructive nuclear technique used to detect mechanical working in the form of deformation effect.To distinguish between valence and core electrons of wrought 5xxx Al-alloys, Doppler broadening line-shape ( $\mathrm{S}$ and $\mathrm{W}$ parameters)have been measured. The effect of the degree of deformation on these parameters has been carried out usingdifferent (5052, 5251 and 5754) Al-Mg alloys samples.An exponential increase in the S-parameter accompanied with an exponential decrease in the $\mathrm{W}$-parameter with increasing the degree of deformation was observed before reaching saturation for both of them. The linearity in the S- versus W-parameters for the investigated $(5251,5052$, and 5754) Al-alloys has been used to identify the defect type.
\end{abstract}

Keywords: Positron annihilation, Doppler broadening line-shape parameters, Al-Mg alloys.

\section{Introduction}

Aluminum alloys grouped into wrought and cast alloys. Wrought alloys which mechanically worked to final shape consist of 4 digits based on major alloying elements, while cast alloys compositions are optimized for casting to final shaped. Wrought $5 \times x \times$ Alalloys, have been studied extensively. They provide good properties, such as high fatigue strength, excellent corrosion resistance, and formability. Furthermore, the improvement of strength and formability in Al-alloys will accelerate the applications to industry as a promising structural material for substituting steels [1-5].Positron annihilation spectroscopy (PAS) technique emerged as the most effective technique in point defect studies because of its high resolution and nondestructive nature. PAS takes advantage of the fact that positively charged positrons tend to localize in open volume regions (e.g., free volume, vacancies, dislocations, voids, etc.), where there are missing positively charged atomic nuclei [6]. Furthermore when a positron and an electron annihilate, the resulting gamma rays yield information about the annihilation site, making PAS a sensitive probe for vacancies. Studying the positron annihilation process characteristics can detect the state of electrons in metallic substances [7].

\section{Doppler Broadening}

In order to observe the evolution of defects and to monitor the damage process directly, the positron annihilation Doppler Broadening (DB) technique has been used. Upon trapping, a positron annihilates with an electron into two $511 \mathrm{KeV}$ photons. The detection of the slight differences in energy of the $0.511 \mathrm{MeV}$ annihilation quanta due to the energy and momentum of the electron in the positronelectron annihilation is the basis of Doppler broadening measurements. A distribution spectrum of the number of counts versus annihilation quanta energy in a given material is collected, resulting in a nearly Gaussianlooking peak at $0.511 \mathrm{MeV}$ as shown in Fig.1. In an annihilation spectrum these shifts lead to a broadening of the $511 \mathrm{keV}$ photo peakswhich is quantified by the $\mathrm{S}$ - and $\mathrm{W}$-parameters [8]. S- and W- parameters reflect annihilations with valence and core electrons, respectively, therefore ideal to monitor the generation and evolution of deformation induced defects and the chemical environment at the positron trapping sites. S-parameter is the ratio of the area under the central part of the peak to the total area and $\mathrm{W}$-parameter being the ratio between the area under the wings of the peak and the total area. A material with a higher $\mathrm{S}$ value will have more defects than a material with a lower $\mathrm{S}$ value [9].

\footnotetext{
*e-mail: emad.badawi@mu.edu.eg

**e-mail: m_abdelrahman@mu.edu.eg

DOI :10.21608/ejphysics.2017.4743
} 


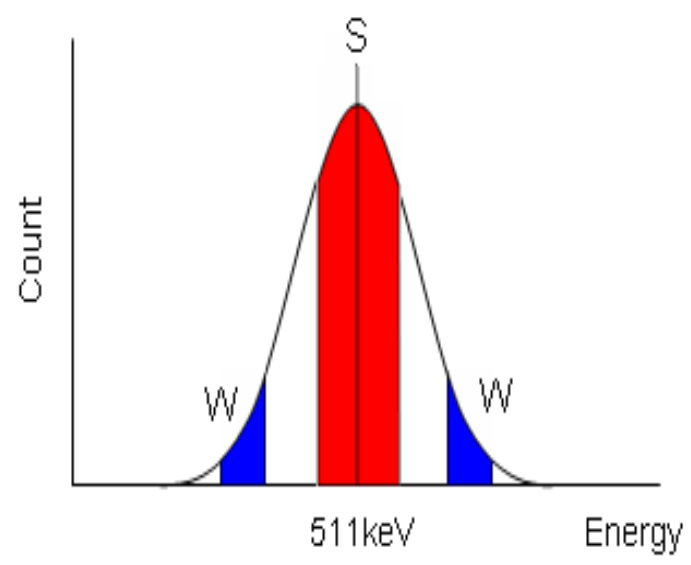

Fig. 1. Schematic representation of $\mathrm{S}$ - and Wparameter regions.

\section{Description of the experimental method}

The system used in the present work to determine the Doppler broadening $\mathrm{S}$ - and W-parameters, consists of an Ortec High Purity Germanium (HPGe) detector, with an energy resolution of $1.5 \mathrm{keV}$ for the $511 \mathrm{keV}$ line of ${ }^{22} \mathrm{Na}$, an Ortec $3 \mathrm{keV}$ bias supply as shown in Fig. 2. The signal coming from the detector enters the input of a preamplifier and the output from the preamplifier is fed to amplifier. The output signal from the amplifier is fed to the input of an ADC to be digitized. Then the signal passes to the MCA that transfers the data to the computer system.
Samples of Al-Mg alloys (5251 5052 and 5754) with chemical composition shown in Table 1 and of dimensions (170x150 x2.98 $\mathrm{mm}^{3}$ ) have been chosen for the experiment. The investigated samples were polished chemically by phosphoric acid based processes then annealed at $773 \mathrm{~K}$ for $10 \mathrm{hr}$. Samples under investigation were subjected to different degree of deformation at room temperature. ${ }^{22} \mathrm{Na}$ positron source was sandwiched between two identical samples for each measurement.

\section{Results and Discussions}

The line shape parameters; S- and Wparameters as a function of thickness reduction for all investigated samples (5251, 5052, and 5754) are shown in Fig. 3 (a\&b) 4 (a\&b) and 5 (a\&b), respectively. The general behavior of the S-parameter for all the investigated samples is found to be an exponential increase before reaching saturated value at a definite thickness reduction, while $\mathrm{W}$-parameter reveals an exponential decay before reaching stability. The values that describe the behavior of S- and $\mathrm{W}$ - parameters for all samples are shown in Table 2.

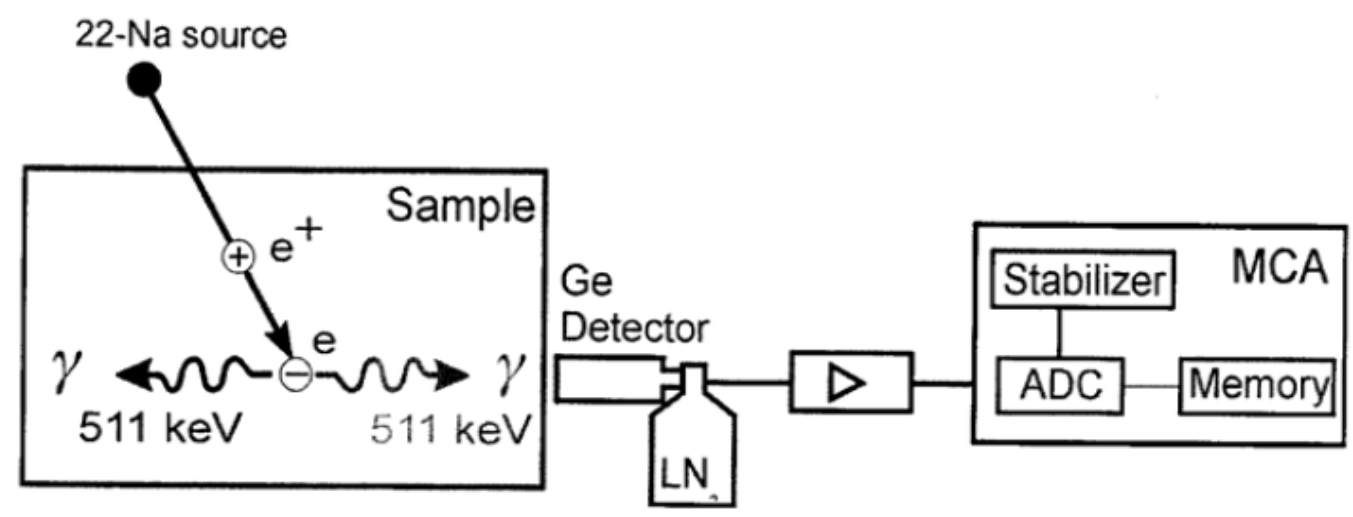

Fig. 2. Block diagram of HPGe-detector and electronics for doppler broadening line-shape studies.

TABLE 1. The chemical composition of the investigated (5251, 5052 and 5754) Al-alloys.

\begin{tabular}{ccccccccc}
\hline Alloy & $\mathbf{S i}$ & $\mathbf{F e}$ & $\mathbf{C u}$ & $\mathbf{M n}$ & $\mathbf{M g}$ & $\mathbf{C r}$ & $\mathbf{Z n}$ & Al \\
\hline 5251 & 0.4 & 0.5 & 0.15 & $0.1-0.5$ & 2.2 & 0.1 & 0.25 & Reminder \\
5052 & 0.25 & 0.4 & 0.1 & 0.1 & 2.25 & 0.15 & 0.15 & Reminder \\
5754 & 0.4 & 0.4 & 0.111 & 0.5 & 3.15 & 0.3 & 0.2 & Reminder \\
\hline
\end{tabular}

Egypt. J. Phys. Vol. 45 (2017) 

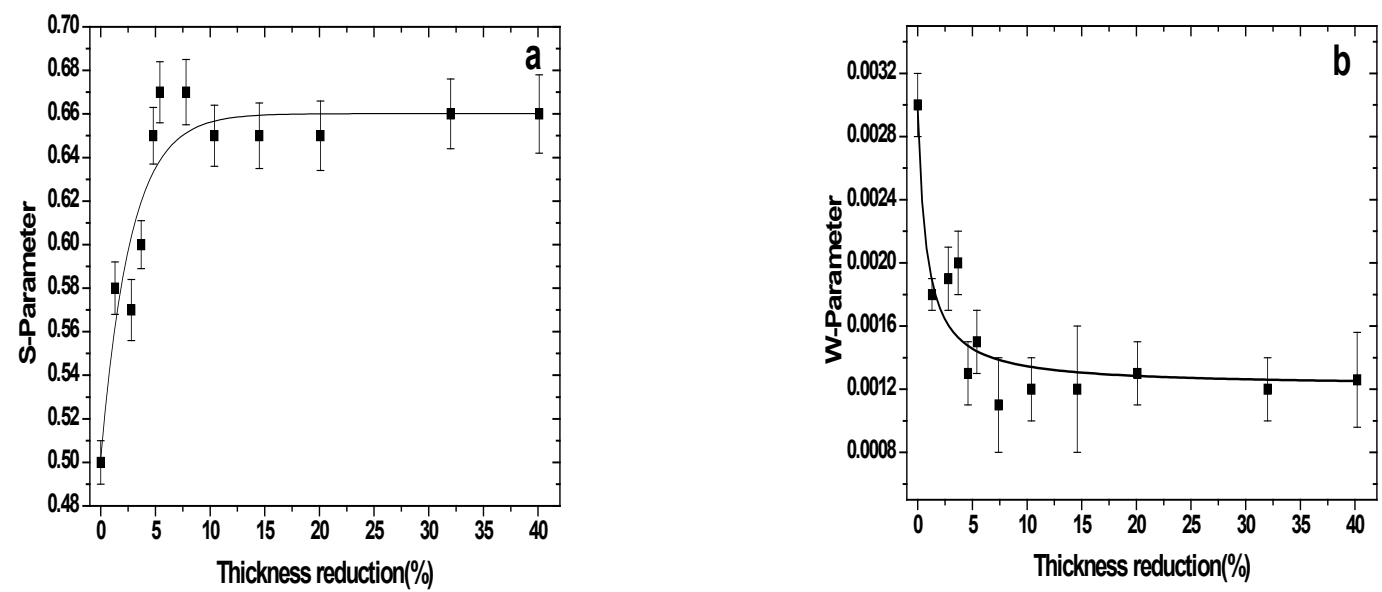

Fig. 3. The variation of Doppler broadening line-shape parameters with thickness reduction of 5251Al-alloy, (a): S-parameter and (b): W- parameter.

TABLE 2. Information of S- and W-parameters for the investigated samples.

\begin{tabular}{|c|c|c|c|}
\hline Sample & 5251 Al-alloy & 5052 Al-alloy & 5754 Al-alloy \\
\hline $\begin{array}{c}\text { Annealed S- parameter } \\
\text { value }\end{array}$ & 0.50 & 0.60 & 0.52 \\
\hline $\begin{array}{l}\text { Saturated S- parameter } \\
\text { value }\end{array}$ & 0.65 & 0.69 & 0.60 \\
\hline $\begin{array}{l}\text { General behavior of } \\
\text { S-parameter }\end{array}$ & An exponential increase & An exponential increase & An exponential increase \\
\hline $\begin{array}{c}\text { Increase stage of } \\
\text { S-parameter value }(\%)\end{array}$ & $\begin{array}{l}\text { Up to approximately } 8.00 \\
\% \text { thickness reduction }\end{array}$ & $\begin{array}{l}\text { Up to approximately } \\
12.00 \% \text { thickness } \\
\text { reduction }\end{array}$ & $\begin{array}{l}\text { Up to approximately } 15.00 \% \\
\text { thickness Reduction }\end{array}$ \\
\hline $\begin{array}{l}\text { Annealed W-parameter } \\
\text { value }\end{array}$ & 0.0030 & 0.0080 & 0.0032 \\
\hline $\begin{array}{l}\text { Saturated W-parameter } \\
\text { value }\end{array}$ & 0.0012 & 0.0010 & 0.00175 \\
\hline $\begin{array}{l}\text { General behavior of } \\
\text { W-parameter }\end{array}$ & An exponential decrease & An exponential decrease & An exponential decrease \\
\hline $\begin{array}{c}\text { Decrease stage of } \\
\text { W-parameter value (\%) }\end{array}$ & $\begin{array}{l}\text { Up to approximately } 7.50 \\
\% \text { thickness reduction }\end{array}$ & $\begin{array}{c}\text { Up to approximately } \\
12.00 \% \text { thickness } \\
\text { reduction }\end{array}$ & $\begin{array}{l}\text { Up to approximately } 15.00 \% \\
\text { thickness reduction }\end{array}$ \\
\hline
\end{tabular}


The S-annihilation parameter as a function of the $\mathrm{W}$-annihilation parameter is depicted in Fig. 6. Liszkay et al. [10] suggested a method for data analysis which directly shows that the same type of defect can be present in a set of samples by checking the linearity of the S- versus $\mathrm{W}$ - parameter. The S-parameter is associated mainly with the annihilation of positrons with valence electrons. W-parameter is associated with the annihilation of positrons with core electrons. If the regions, used for the calculation of S-and W-parameters are not adjacent, a linear relationship between $\mathrm{S}$ and $\mathrm{W}$ can occur in two cases:

(i) If in the samples, besides annihilation of free positrons, there is only one type of defects

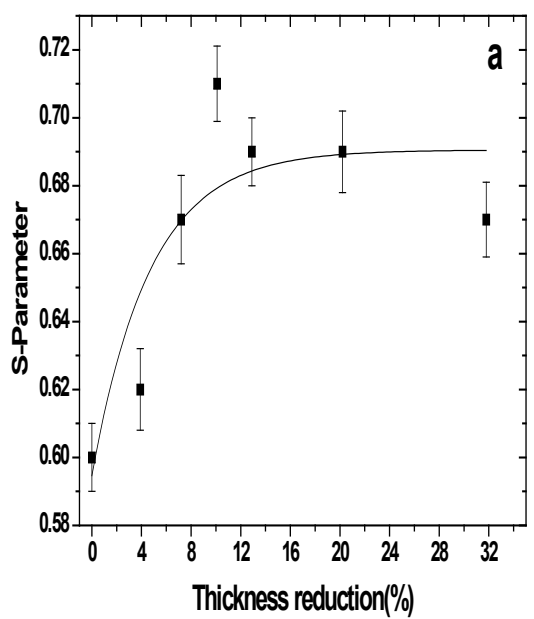

trapping positrons. In the case of existing of several types of defects, one of them must be predominant.

(ii) If it can be assumed that several annihilation species are formed in the samples at $t=0$, and they proceed to annihilation without interconversion, provided that certain relationships between the relative concentration of the species exist.

From Fig. 6, it looks that both samples 5754 and 5251 have approximately identical linearity which means that they have the same type of defect. Meanwhile, the other sample 5052 has different trend of linearity which probably related to the presence of different type of defect.

Fig. 4. The variation of Doppler broadening line-shape parameters with thickness reduction of 5052Al-alloy, (a):S-parameter and (b):W- parameter.
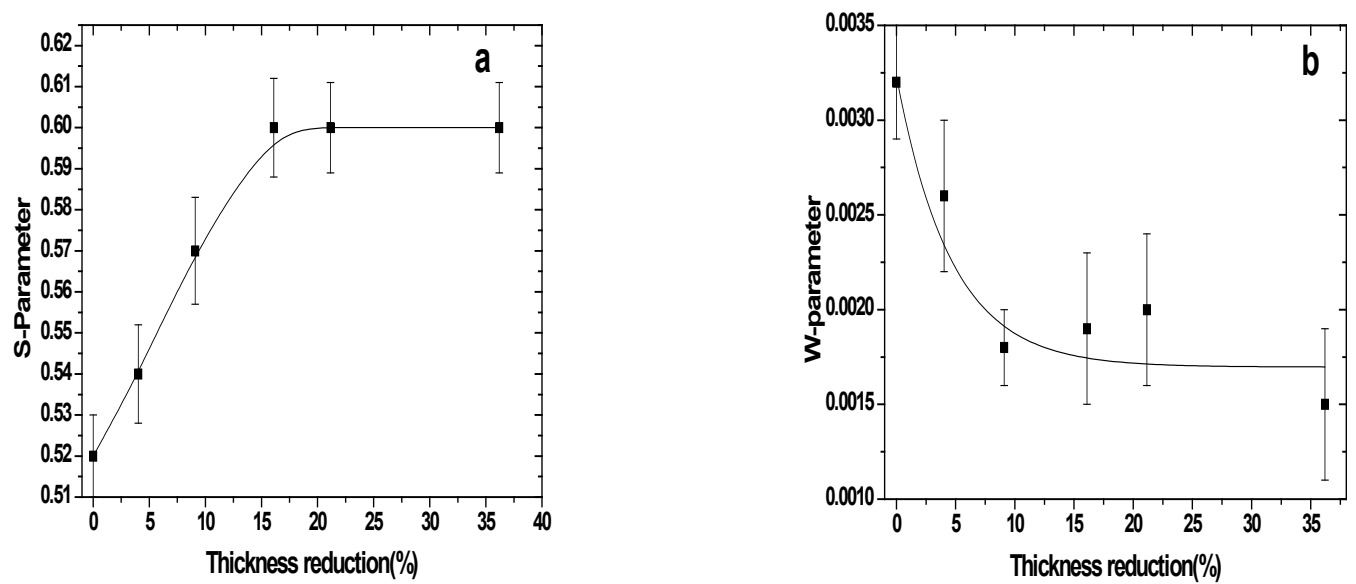

Fig. 5. The variation of Doppler broadening line-shape parameters with thickness reduction of 5754Al-alloy, (a): S- parameter and (b): W- parameter.

Egypt. J. Phys. Vol. 45 (2017) 


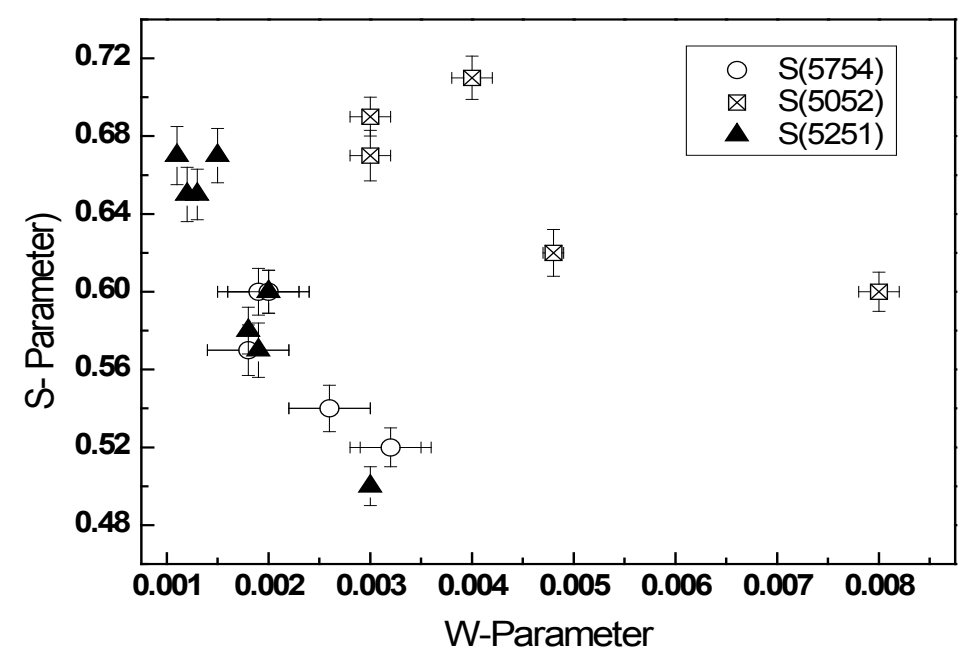

Fig. 6. S- versus W-parameters for the investigated (5251, 5052, and 5754) Al-alloy.

\section{Conclusions}

- Doppler broadening is a sensitive nondestructive nuclear technique to detect the degree of deformation of $(5251,5052$, and 5754) Al-alloys.

- S- Parameter showed an exponential increase, while W- parameter decreased exponentially with increasing the degree of deformation before reaching saturation for both parameters.

- The increase stage for S- parameter refers to an increase of the percentage of the annihilations with valance electrons which indicates an increase in the defect density. The decrease stage for the W-parameter refers to decline in the percentage of the annihilation with core electrons or by other words with bulk material.

- The linearity in the S- versus W-parameters indicates that both Al-5754 and Al-5251 have the same type of defect, while Al5052 sample probably has different type of defect. So thatDoppler broadening lineshape parameters can be used to distinguish between different types of defects.

\section{References}

1. Evancho, J.W. and Kaufman, J.G., Aluminum. 53, 609 (1977)

2. Altenpohl, D.G., Aluminum Technology Applications and Environment, A Profile of A Modern Metal, 6th ed. TMS, Ohio, 1998, 360.
3. Troeger, A.N. and Starke, E.A., J. Mater Sci. Eng. A. $277,102(2000)$.

4. Davis, J.R., ASM Handbook, vol. 2, ASM, Metals Park, USA, 1990.

5. Vetrano, J.S., Bruemmer, S.M., Pawlowski,L.M. and Robertson, I.M., Mater Sci. Eng. A. 238,101 (1997).

6.Hautojarvi, P. and Corbel, C., Positron Spectroscopy of Solids, In Proceedings of the International School of physics "Enrico Fermi", Course CXXV. Varenna, Italy, IItalian Physical Society (1995).

7.Ahmed Gamal Attalah, Study of some properties ofAl-alloys using non-destructive nuclear technique "Positron Annihilation Technique (PAT)", Master thesis (2013).

8.Hautakangas, S., Schut, H., van der Zwaag S., Rivera Diaz Del Castillo,P. E. J. and van Dijk, N.H., Positron annihilation spectroscopy as a tool to develop self-healing in aluminium alloys, Phys. Status Solidi (c). 4 -10 3469 (2007).

9.Coleman, P.G. (Ed.), Positron Beams and their applications, WorldScientific Publishing Co., Singapore (2000).

10.Liszkay, C. Corbel, L. Baroux, P. Hautojarvi, M. Bayhan, A. W. Brinknlan, and Tatarenko, S., Appl. Phys. Lett. 64, 11,1380 (1994).

(Received:28/10/2016; accepted:23/1/2017)

Egypt. J. Phys. Vol. 45 (2017) 


\section{استكثاف عيوب بعض سبائك الومنيوم التجارية باستخدام تقتية استعر اض دوبلر}

عماد بلوي و محمد عبدالرحمن و احمد جمال وممدوح عبدالناصر

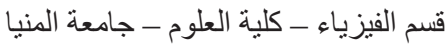

تعتبر طريقة استعر اض أو اتساع دوبلر للفناء البوزيترونى تقنية نووية حساسة غير مدمرة تستخدم

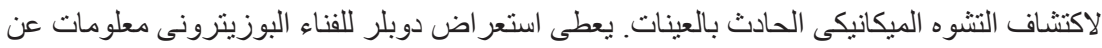

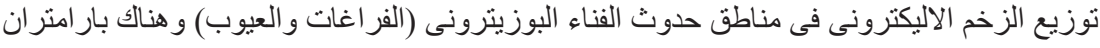

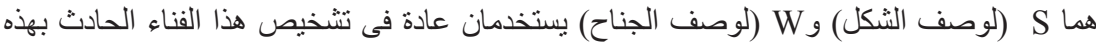

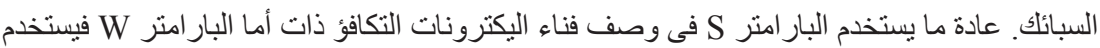
فى وصف فناء الاليكترونات الأساسية.xxx. تم تعيين بار امترات الثكل(S and W parameters)

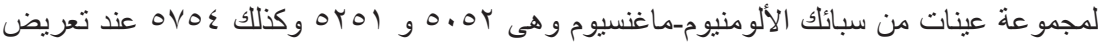

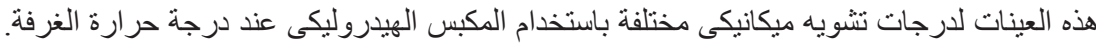

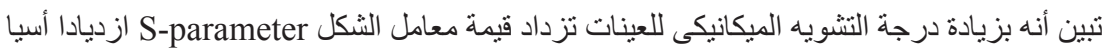

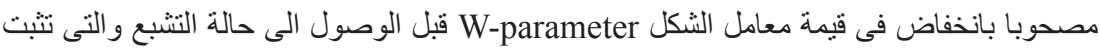

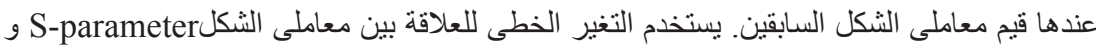
فW-parameter 